\title{
Análise crítico-compreensiva da Base Nacional Comum Curricular voltada para os conteúdos de Geografia Física na Educação Básica
}

\author{
A critical and reflective analysis of the National Curriculum Common Core focused \\ on the contents of Physical Geography in the Basic Education
}

\author{
CRUZ $^{1}$, F. H. A.; CASTRO ${ }^{2}$, A. F. G.; PINTO ${ }^{3}$, D. A. N.; BARBOSA ${ }^{4}$, M. E. S. \\ herbstergeo@gmail.com
}

\begin{abstract}
Resumo
O presente artigo tem por objetivo realizar uma análise crítico-compreensiva das propostas curriculares preliminares da Base Nacional Comum Curricular, documento que se encontra em estágio de elaboração e visa estabelecer direitos e objetivos de aprendizagem e desenvolvimento para as etapas e modalidades da Educação Básica. Utiliza como metodologia o levantamento e revisão bibliográfica de documentos oficiais como a Lei de Diretrizes e Bases da Educação, o Plano Nacional de Educação e a própria BNCC, além de textos acadêmicos voltados para currículo e ensino, tendo a abordagem qualitativa como princípio norteador a possibilitar maior compreensão das nuanças e dos discursos contidos na argumentação legal. Questiona os interesses e as finalidades da construção de uma base curricular nacional no contexto da existência de documentos similares; descreve os direitos e objetivos de aprendizagem e desenvolvimento voltados para a Geografia, com foco nos conteúdos de Geografia Física; e preconiza um currículo ideal, onde a formação processual e socioconstrutivista do educando são mais importantes que os processos de avaliação.
\end{abstract}

Palavras-chave: Políticas curriculares; Base Nacional Comum Curricular; conteúdos de Geografia Física.

\begin{abstract}
This paper aims to conduct a critical and comprehensive analysis about the primary curriculum program of the National Curriculum Common Core, a document that is in preparation stage and aims to establish the rights, learning and development goals for the steps and procedures of the Basic Education. Used as methodology the survey and literature review of official documents, such as the Law of Education Guidelines and Bases, the National Education Plan and own document under construction; as well as academic texts focused on curriculum and teaching, with a qualitative approach as a guiding principle of the discussions, enabling greater understanding of the nuances and speeches contained in the legal argument. Inquire the interests and goals of construction a national curriculum based on the context of the existence of similar documents; describes the rights and learning and development goals contained face geography, focused on Physical Geography and recommends an ideal curriculum, where the procedural training and social constructivist in the educational formation are more important than the evaluation process.
\end{abstract}

Keywords: Curriculum politics; National Curriculum Common Core; Physical Geography contents.

\section{INTRODUÇÃO}

A Base Nacional Comum Curricular está fundamentada e preconizada pela Lei de Diretrizes e Bases da Educação Nacional (LDB, Nº 9.394/1996) e pelo Plano Nacional de Educação (PNE, No 13.005/2014). Característica comum aos documentos legais ligados à educação, é fruto mais das decisões direcionadas pelo Ministério da Educação (MEC), do que pelos reais interesses dos atores do campo educacional brasileiro, dos movimentos sociais organizados na cidade e no campo e dos professores da Educação Básica.

${ }^{1}$ Francisco Herbster Alencar Cruz, graduando em Geografia/Programa de Educação Tutorial - PET-MEC/SESu, Universidade Federal do Ceará, Fortaleza-CE, Brasil.

${ }^{2}$ Antônio Fernando Gomes de Castro, graduando em Geografia/Programa Institucional de Bolsa de Iniciação à Docência - PIBID, Universidade Federal do Ceará, Fortaleza-CE, Brasil.

${ }^{3}$ Deborah Amorim Noberto Pinto, graduanda em Geografia/Programa de Educação Tutorial - PET-MEC/SESu, Universidade Federal do Ceará, Fortaleza-CE, Brasil.

${ }^{4}$ Maria Edivani Silva Barbosa, professora doutora do Departamento de Geografia/Coordenadora do Programa Institucional de Bolsa de Iniciação à Docência - PIBID/Geografia, Universidade Federal do Ceará, Fortaleza-CE, Brasil. 
Tais fundamentos legais são questionados por autores que teorizam o currículo enquanto conjunto de disposições normativas e balizadoras da Educação Básica. Se torna necessário compreender as contradições, nuanças e antagonismos que tal processo de elaboração de um currículo pressupõe, para além de uma visão utilitarista. Esse mesmo documento estabelece direitos e objetivos de aprendizagem e desenvolvimento voltados para a Geografia, onde os conteúdos de Geografia Física são empobrecidos, desvalorizados e sua base teórica é descrita equivocadamente.

Para que todos os objetivos, finalidades e diretrizes contidos se tornem realidade na vida escolar cotidiano no País é primordial a articulação entre os sistemas de educação. Uma das propostas da BNCC é criar um Sistema Nacional de Educação (SNE), decorrente da integração de quatro políticas, a saber: Política Nacional de Formação de Professores; Política Nacional de Materiais e Tecnologias Educacionais; Política Nacional de Avaliação da Educação Básica e a Política Nacional de Infraestrutura Escolar.

Partindo dessa perspectiva e diante de um contexto nacional diverso, onde as disparidades regionais são latentes e as políticas educacionais são concebidas visando uma "generalização/homogeneização" de seus objetivos, metas e formas de avaliação, é primordial questionar as atribuições, direitos e objetivos de aprendizagem e desenvolvimento contidos nas propostas da BNCC para a Geografia, nas etapas da Educação Básica, com destaque para os conteúdos de Geografia Física; a que e a quem se destina a construção de um currículo comum nacional; e quais os interesses e discursos contidos nas propostas como questões norteadoras do presente trabalho.

\section{METODOLOGIA}

A análise aqui empreendida tem por metodologias o levantamento e a revisão bibliográfica; interpretação de documentos oficiais como a Lei de Diretrizes e Bases da Educação Nacional, o Plano Nacional de Educação e as propostas da consulta pública da Base Nacional Comum Curricular, tendo a abordagem qualitativa como norteadora das discussões e concepções de educação, escola, conteúdos e currículo.

O levantamento bibliográfico e a análise documental têm por objetivos, conforme Marconi e Lakatos (2010, p. 142) "fornecer dados atuais e relevantes relacionados com o tema", se constituindo como elemento primordial na elaboração de uma pesquisa. A delimitação do tema, das fontes a serem utilizadas e a seleção dos métodos e técnicas o sucedem.

A análise documental, por meio da abordagem qualitativa, propicia a compreensão do documento e suas especificidades, sendo primordial a correlação com outras fontes que embasam 
sua discussão, como textos acadêmicos, por exemplo. Segundo as referidas autoras, a abordagem qualitativa tem por características a compreensão de dados fundamentada em um olhar integral dos fenômenos, a ressaltar as contradições e os movimentos contidos em tal processo.

\section{RESULTADOS E DISCUSSÃO}

A BNCC: perspectivas e base legal

Como fruto de uma argumentação legal que legitima e fundamenta a elaboração de uma base nacional comum, documentos oficiais como a LDB, em seu artigo vinte e seis, dispõe sobre uma formação básica que abrange áreas tidas como essenciais, como Língua Portuguesa e Matemática. Essa base tem por fundamento, conforme Carneiro (2015, p.318), "a garantia de concretização do princípio de equidade, com educação básica de qualidade para todos”, e se articula com a "parte diversificada", que abrange outras temáticas e áreas.

O PNE, com vigência de dez anos (2014-2024), em suas metas e estratégias para alcançar os objetivos propostos, preconiza a formulação de uma base nacional comum voltada para a Educação Básica. Em seu artigo sétimo, salienta a colaboração entre os diversos sistemas educacionais do País; na meta sétima, para alcançar determinados indicadores do Índice de Desenvolvimento da Educação Básica (IDEB) visa "estabelecer e implantar, mediante pactuação interfederativa, diretrizes pedagógicas para a Educação Básica e a base nacional comum dos currículos, com direitos e objetivos de aprendizagem e desenvolvimento (...)” (BRASIL, 2014, p.60). Ambas comungam e convergem para a sustentação e implementação de uma base nacional curricular de caráter comum.

Tendo por fundamentação legal as determinações contidas nessas leis, a BNCC tem por proposta a criação de um Sistema Nacional de Educação (SNE) que integre os demais sistemas, tendo como prioridade estabelecer os direitos e objetivos de aprendizagem e desenvolvimento específicos de cada componente curricular e que variam em cada modalidade e série da Educação Básica, levando em consideração as características de cada fase do desenvolvimento psicogenético em que o aluno se encontra; estabelece intencionalidades e perspectivas para cada etapa do processo educativo formal. Como expresso no documento, "não há concretização de objetivos de aprendizagem sem a consideração dos reais sujeitos de aprendizagem " (BRASIL, p. 31, 2016).

Apesar da argumentação legal fortalecer o discurso favorável, educadores de todo o País discutem as reais intencionalidades e perspectivas contidas na elaboração de uma base nacional comum para os currículos da Educação Básica. Alguns a compreendem como fruto de um processo 
maior que insere interesses neoliberais e de grupos específicos nas políticas educacionais; não raro, há críticas enquanto às reais necessidades expressas em tal documento diante de outros que apresentam similaridades enquanto aos seus princípios, objetivos e métodos.

Silva (2015) discute os conceitos de educação, formação humana e políticas curriculares, direcionando suas observações à BNCC. Conforme a autora, um currículo não é apenas o resultado de uma listagem de objetivos, metas e formas de avaliação "travestidos em [direitos] e objetivos de aprendizagem e desenvolvimento [na BNCC]", mas deve ser compreendido enquanto "fazer propriamente dito, as ações por meio das quais se realiza o processo formativo no tempo-espaço da escola" (idem, p. 370). Essa noção de currículo na qual as propostas estão estruturadas conduz a uma "formação administrada", restringida, pré-determinada.

Isto evidencia o caráter de intencionalidade formativa contida no documento, voltado para a instrumentalização técnica e laboral em detrimento de uma experiência formativa genuína dos educandos, o que não condiz com as características processuais e sociointeracionistas desejáveis para o processo educativo crítico e emancipatório.

Enquanto processo que se desdobra em contexto global, envolvendo outros atores. Macedo (2014) identifica as articulações entre redes diversas dos setores público e privado ligadas à educação como as grandes empresas de comunicação e as corporações transnacionais que imprimem, nas propostas curriculares, como no Common Core (Marco Comum) nos EUA e na BNCC no Brasil, seus mesquinhos interesses. Esses interesses marcadamente neoliberais, mercantilistas e utilitaristas transformam a educação em mercadoria, em "moeda de troca". Nas palavras da autora: "trata-se de uma luta muito mais nuançada do que, possivelmente, nossas ferramentas teóricas nos possibilitam entender" (MACEDO, 2014, p.1545)

Silva (2015) e Macedo (2014) ressaltam o currículo enquanto produto de uma determinada sociedade, delimitada num espaço-tempo dotado de contradições, ideologias e referenciais antagônicos de educação, escola, conteúdos, direito, aprendizagem etc. No contexto brasileiro, onde os interesses políticos superpõem e influenciam a construção de currículos em detrimento do bem comum, essas características são perceptíveis.

Comungando dessas mesmas perspectivas e tendo por base outros documentos oficiais que tratam de um currículo comum em âmbito nacional, e fazendo uma crítica ferrenha à BNCC, Ferreira (2015) destaca a inutilidade de constituição de mais um documento oficial que visa integrar os sistemas educacionais do País. Os PCN, a LDB e a própria Constituição Federal já pressupõem essa articulação. Para a autora “(...) não faz sentido político, social e muito menos educacional o propósito de 'criar um novo[sic] currículo' de base comum para o Brasil, porque já existem inúmeros documentos oficiais brasileiros que tinham/têm o mesmo propósito" (Idem. p. 309). 
A Geografia na BNCC: o que é proposto para os conteúdos de Geografia Física?

Em linhas gerias, cabe à Geografia: "articular compreensões de mundo, de lugares de vivências e de linguagens, bem como conhecimentos científicos produzidos (...), visando ao desenvolvimento de leituras críticas do mundo" (BRASIL, 2016, p. 160). Foca no processo de alfabetização dos educandos nos anos iniciais do Ensino Fundamental e no uso de linguagens diversas, como a cartográfica durante todas as etapas da Educação Básica. A BNCC compreende a Geografia e suas correntes teórico-metodológicos enquanto Ciência sistematizada, porém, apresenta forte ecletismo conceitual e ambiguidades enquanto aos conceitos-chave dessa Ciência - a saber: espaço, região, território, lugar e paisagem - descrevendo-os equivocadamente.

Na elaboração dos Parâmetros Curriculares Nacionais, na década de 1990 no governo Fernando Henrique Cardoso (1994-2002), a situação não foi diferente: prevaleceram os interesses privados neoliberais em sua constituição que, segundo Carlos e Oliveira (1999, p.105), foram elaborados sem considerar a diversidade do povo brasileiro, atentando apenas para os problemas educacionais de maior destaque. No caso do currículo de Geografia, como nos conteúdos de Geografia Física, foi marcado por diversas concepções, como marxistas, fenomenológicas e positivistas, mostrando ecletismo e ambiguidade conceitual, o que é perceptível nas propostas da BNCC.

\section{A Geografia nos anos iniciais do Ensino Fundamental}

A formulação de uma base nacional comum consegue ser referência para um País tão heterogêneo como o Brasil? Na sua elaboração ela consegue ouvir as ideias das classes populares? Os professores da Educação Básica tiveram chances de serem ouvidos? Algumas orientações contidas na BNCC são contraditórias, o que é evidente nos conteúdos de Geografia Física, onde a compartimentação/fragmentação leva ao empobrecimento das discussões, potencializando a nociva e desnecessária dicotomia presente na Geografia entre Física e Humana, a desconsiderar suas articulações. Compreende ambas como independentes e desarmoniosas; um desserviço à Geografia.

Em relação à participação dos setores populares, provavelmente suas propostas foram minimizadas diante das cerca de doze milhões de contribuições enviadas. Os professores, maiores interessados na Base, primordialmente deveriam ter local privilegiado nos debates e encontros, e suas colaborações não deveriam ser suprimidas por outros interesses, como os mercantis do setor 
privado, que ampliaram gradativamente sua ação sobre a educação pública (PERONI e CAETANO, 2015, p. 338).

A BNCC repetidas vezes aborda o termo "vivência", que integra o conceito de lugar de acordo com as concepções teórico-metodológicas da Geografia Humanista, definido como algo familiar ao sujeito, espaço de vivências, o já experienciado (CAVALCANTI, 1998, p.88). O documento atenta para outros conceitos - paisagem, região e território - os quais são fundamentais para o ensino de Geografia e suas distintas áreas.

Com a valorização do conceito de lugar o documento evidencia que o papel da Geografia nos anos iniciais do processo de escolarização é o "saber localizar-se" (BRASIL, 2016, p.160), colocando em segundo plano a compreensão, discussão e reflexão das transformações socioespaciais da Geografia, que compreende as relações sociedade-natureza no espaço geográfico. Deveras, empobrece conteúdos como relevo, hidrografia e climatologia, por seres "complexos demais para tal período". Essa argumentação é falha e mesquinha, pois esses conhecimentos são importantes para os educandos no seu fazer geográfico cotidiano.

\section{A Geografia nos anos finais do Ensino Fundamental}

A Geografia nos anos finais do Ensino Fundamental se caracteriza pela complexificação das discussões, conteúdos, atribuições e objetivos de aprendizagem e desenvolvimento já evidenciados nas etapas anteriores, o que não pressupõe a descrição dos objetivos voltados para os conteúdos de Geografia Física, que se limitam cada vez mais e são reduzidos à mera atividade contemplativa. Entretanto, a utilização de fontes diversas como referências de pesquisas, a serem feitas por meio de discussões e trabalhos de apresentação, é uma das novidades apresentadas como possibilidade e que se amplia no Ensino Médio.

Os agentes escolares - educandos e professores, principalmente - ganham diversas atribuições/características nessa etapa: aos professores caberia o exercício de propiciar e incentivar a criatividade e autonomia dos educandos; os alunos são compreendidos enquanto produtores de conhecimento, agentes ativos e envolvidos no processo de ensino-aprendizagem, onde os seus conhecimentos e informações prévios devem ser levados em consideração.

Passini (2013, p.73) salienta que a articulação entre conteúdo trabalhado em sala de aula por meio das matérias dispostas no currículo e sua possível articulação com os conhecimentos, informações e saberes trazidos pelos alunos podem propiciar um conhecimento melhorado, que alia as dimensões empírica e científica com fins de ampliação do conhecimento: de informações muitas vezes desconexas para produção de conhecimento científico sistematizado. O ensino de Geografia 
Física se insere nessa perspectiva com intuito de agregar aos conhecimentos de lugar de vivências conceito-chave da BNCC - os pressupostos da base natural, onde a sociedade produz seu espaço e estabelece suas relações, desconstruindo discursos e práticas dicotômicas.

\section{A Geografia no Ensino Médio}

Para o Ensino Médio, a BNCC toma como base as Diretrizes Curriculares Nacionais para o Ensino Médio (DCNEM, Lei No 9.131/1995), tendo a reflexão crítica e o desenvolvendo de capacidades e habilidades como pontos que enfatizam a preparação do jovem para os desafios da vida adulta, na perspectiva de uma educação emancipadora e cidadã. Nessa etapa, como já evidenciado anteriormente, a pesquisa se torna um dos pontos mais relevantes, onde é enfatizado o seu papel na busca constante de respostas de forma autônoma e para a construção de conhecimento.

Essa etapa visa uma maior capacidade do aluno para desenvolver habilidades, reconhecer múltiplas linguagens e para o uso das tecnologias, de modo que este passe a compreender os diferentes processos de formação do espaço geográfico. Os objetivos de aprendizagem e desenvolvimento direcionados à Geografia correspondem à articulação entre "trabalho, ciência, tecnologia e cultura na perspectiva da emancipação humana" (BRASIL, 2016, p.633), além das seguintes unidades curriculares: linguagens e tecnologias na produção do conhecimento geográfico; dinâmicas da natureza e questão ambiental; Brasil: território e sociedade; dinâmicas populacionais, fluxos e movimentos sociais; cidade e campo no mundo; globalização e configuração do espaço mundial; geopolítica e conflitos no mundo atual.

Os conteúdos de Geografia Física nessa etapa têm papel de integração: não devem ser compreendidos isoladamente dos fenômenos sociais nem das vivências cotidianas dos alunos. Relaciona a hidrografia com o uso e ocupação do solo nas margens do rio e seus afluentes; o relevo, com a presença das estruturas fundiárias predominantes, por exemplo. Aprendizagem significativa se dá por essa articulação entre conhecimentos sistematizados e cotidiano.

Devemos compreender essa etapa final da Educação Básica como propiciadora de prosseguimento de estudos, onde se almeja uma formação processual, tendo as relações sociointeracionistas como perspectiva norteadora a construir as bases para uma formação cidadã necessariamente crítica e transformadora da realidade, a ultrapassar os objetivos utilitaristas dos processos de avaliação tão presentes nas propostas curriculares e no ambiente escolar.

Os conteúdos de Geografia Física e BNCC 
Os conteúdos de Geografia Física se inserem na BNCC como auxiliadores dos demais conteúdos do componente curricular, onde a associação entre sociedade-natureza permeia as propostas como, também, o conceito de lugares de vivência articulado com os conhecimentos das diversas áreas, como geomorfologia, climatologia, hidrogeografia etc. Tem por objetivo primordial a inserção do educando na perspectiva integralista da natureza, onde a sociedade produz seu espaço e constrói relações.

Entretanto, é empobrecida pelas ambiguidades contidas nas descrições de tais conteúdos, de modo que o norteamento necessário para a aplicação de tais saberes na realidade da Educação Básica, se torna um desafio a mais, posto que os interpretadores das propostas são inseridos, pelo próprio documento, em concepções variadas e rasas sobre os conceitos-chaves da Geografia.

\section{CONSIDERAÇÕES FINAIS}

Compreender o papel das políticas curriculares enquanto norteadoras e estabelecedoras de diretrizes para os currículos da Educação Básica e das propostas enquanto formuladoras de direitos e objetivos de aprendizagem e desenvolvimento se mostram de fundamental importância para os profissionais professores e demais atores do campo educacional. As contradições, nuanças e conceitos diferenciados de direito, aprendizagem, educação, escola, ensino, currículo, relevo, hidrografia, climatologia e os conceitos-chaves da Geografia, são evidenciadas por meio da análise dos discursos contidos nos documentos oficiais, possibilitando sua desconstrução.

A BNCC entra nesse contexto como uma tentativa do Estado brasileiro, por meio de políticas curriculares, de estabelecer um nível comum de conteúdos a serem trabalhados nas escolas, com objetivo à equidade, tanto no acesso quanto na qualidade. Serve a interesses escusos, marcadamente neoliberais, utilitaristas, mercantilistas, mesquinhos e privados; se mostrou desnecessário devido à existência de outros parâmetros e diretrizes que versam sobre as mesmas atribuições, objetivos e metas contidas em suas propostas; além das ambiguidades conceituais.

O papel da Geografia nos anos iniciais do Ensino Fundamental, dentro da perspectiva do documento analisado, estaria ligado ao processo de letramento/alfabetização por meio do uso das diferentes linguagens, incluindo a cartográfica; nos anos finais e no Ensino Médio há a complexificação dos conteúdos e das metodologias trabalhadas. Em todas as etapas da Educação Básica deve haver contextualização dos conteúdos com as informações e saberes adquiridos pelos alunos no seu processo formativo; o conceito de lugares de vivências é ressaltado como caminho e perspectiva norteadora para que esses objetivos sejam alcançados. 
Um currículo deve expressar as reais necessidades dos grupos a que é destinado. A BNCC não estaria nesse contexto, posto que prioriza metas, objetivos e formas de avaliação em detrimento do processo de formação do educando. Compreende o currículo enquanto disposições e diretrizes fundamentadas legalmente que visam à formação integral, significativa, participativa, contextualizada e dialógica, tendo como princípio a processualidade formativa do ser humano por meio da perspectiva de ensino-aprendizagem.

\section{REFERÊNCIAS}

BRASIL. MEC. Consulta Pública. Base Nacional Comum Curricular. 2 v. Brasília, 2016. p.652. Disponível em: www.basenacionalcomum.mec.gov.br/documentos/BNCCpdf. Acessado em: 14 jun. 2016.

. Lei n ${ }^{\circ} 13.005$, de 25 de junho de 2014. Aprova o Plano Nacional de Educação - PNE e dá outras providências. Diário Oficial da União, Brasília, DF, 2014. p. 86. Disponível em: www2.camara.leg.br/legin/fed/lei/2014/lei-13005-25-junho-2014-778970-publicacaooriginal144468-pl.html. Acessado em: 13 mai. 2016.

Lei $n^{\circ}$ 9.394, de 20 de dezembro de 1996. Estabelece as Diretrizes e Bases da Educação Nacional. Diário Oficial da União, Brasília, DF, 23 dez. 1996. p.64. Disponível em: www.planalto.gov.br/ccivil_03/leis/L9394.htm. Acessado em: 14 mai. 2016.

. Lei 9.131 de 25 de novembro de 1995. Estabelece as Diretrizes Curriculares Nacionais do

Ensino Médio. Diário Oficial da União, Brasília, DF, 2013 p.8. Disponível em: www.portal.mec.gov.br/seb/arquivos/pdf/res0398.pdf. Acessado em: 17 jul. 2016.

CARNEIRO, M. A. LDB fácil: leitura crítico-compreensiva, artigo a artigo. 23 ed. Petrópolis: Vozes, 2015, p. 552.

CAVALCANTI, L. de S.. Geografia escolar e a construção de conceitos no ensino. In: Geografia, Escola e Construção de Conhecimentos. Papirus Editora, Campinas, São Paulo, 1998, p 87-136.

FERREIRA, W. B. O conceito de diversidade no BNCC: relações de poder e interesses ocultos. Retratos da Educação, v. 9, n. 17, p. 299-319. jul./dez. Brasília: 2015. Endereço eletrônico: www.esforce.org.br/index.php/semestral/article/view/582. Acessado em: 17/05/2016.

MACEDO, E. Base Nacional Curricular Comum: novas formas de sociabilidade produzindo sentidos para educação. Revista e-Curriculum, Ano 12, v. 12, n. 03, São Paulo, p.1530-1555 out./dez. 2014. Endereço eletrônico: revistas.pucsp.br/index.php/curriculum/article/viewFile/21666/15916. Acessado em: 21/05/2016. 
MARCONI, M. de A.; LAKATOS, E. M. Fundamentos de metodologia científica. 7. ed. São Paulo: Atlas, 2010, p. 320.

OLIVEIRA, A. U. de. Geografia e ensino: os parâmetros Curriculares Nacionais em discussão. In. CARLOS. A. F. A. E OLIVEIRA, A. U. de (Orgs.). Reformas no mundo da educação - parâmetros curriculares e geografia. São Paulo: Contexto, 1999, p. 156.

PASSINI, E. Y. Prática de ensino de Geografia e estágio supervisionado. São Paulo: Contexto, 2013, p. 224.

PERONI, V. M. V.; CAETANO, M. R. O público e o privado na educação: Projetos em disputa? Retratos da Escola, v. 9, n. 17, p. 337-352, jul./dez. Brasília: 2015. Endereço eletrônico: www.esforce.org.br/index.php/semestral/article/view/584. Acessado em: 15/05/2016.

SILVA, M. R. Currículo, ensino médio e BNCC: um cenário de disputas. Retratos da Escola, v. 9, n. $17, \quad$ p. $367-379 . \quad$ jul./dez. $\quad$ Brasília: 2015. Endereço eletrônico:www.esforce.org.br/index.php/semestral/article/view/586. Acessado em: 18/05/2016.

\section{AGRADECIMENTOS}

Aos que lutam e sonham por uma educação crítica e emancipadora. À professora doutora Maria Edivani Silva Barbosa, pelo paciente e criterioso trabalho de revisão do presente artigo e pelas suas sempre bem-vindas colaborações. Ao Programa de Educação Tutorial - PET-MEC/SESu - do curso de graduação em Geografia da Universidade Federal do Ceará pelo enriquecimento no processo de formação acadêmica por meio das atividades voltadas ao ensino, pesquisa e extensão.

Recebido em: 14/08/2016

Aceito para publicação em: 01/10/2016 